\title{
Endotoxin-Directed Innate Immunity in Tracheal Aspirates of Mechanically Ventilated Human Neonates
}

\author{
KATHERYN E. NATHE, RICHARD PARAD, LINDA J. VAN MARTER, CARA A. LUND, EUGÉNIE E. SUTER, \\ SONIA HERNANDEZ-DIAZ, ELIZABETH B. G. BOUSH, EVA IKONOMU, LEIGHANNE GALLINGTON, JO ANN MOREY, \\ ALENKA M. ZEMAN, MEAGHAN MCNAMARA, AND OFER LEVY \\ Department of Medicine [K.E.N., R.P., L.J.M., C.A.L., E.E.S., E.B.G.B., E.I., L.G., O.L.], Children's Hospital Boston, Boston, \\ Massachusetts 02115; Department of Newborn Medicine [K.E.N., R.P., L.J.M., J.A.M., A.M.Z., M.M.], Brigham and Women's Hospital, \\ Boston, Massachusetts 02115; Department of Epidemiology [S.H.-D.], Harvard School of Public Health, Boston, Massachusetts 02115; \\ Harvard Medical School [K.E.N., R.P., L.J.M., S.H.-D., O.L.], Boston, Massachusetts 02115; Department of Neonatology [K.E.N.], \\ Division of Newborn Medicine, North Shore Medical Center, Partners HealthCare, Salem, Massachusetts 01970
}

\begin{abstract}
Mechanical ventilation of preterm infants is associated with pulmonary inflammation. Intubated infants often develop bacterial tracheal colonization, but little is known about endotoxin in tracheal aspirates (TAs) or the mobilization of innate immunity toward endotoxin, a potent stimulus that contributes to inflammatory disease. We characterized mobilization of endotoxin-directed innate immunity in TAs from an observational cohort of mechanically ventilated neonates. TA supernatants $(n=42$; GA $=23-40 \mathrm{wk}$, postnatal age $=1-71 \mathrm{~d}$ ) were assayed for endotoxin (Limulus amoebocyte lysate assay) and endotoxin-modulating proteins: bactericidal/permeability-increasing protein (BPI), LPS-binding protein (LBP), and soluble cell differentiation antigen 14 (sCD14). TA cellular BPI was measured by ELISA, Western blot, flow cytometry, and bactericidal assay. TA mRNAs encoding endotoxin-modulating proteins were measured by quantitative real-time PCR (qRT-PCR). Endotoxin in TA supernatants was proportional to both postnatal age and polymorphonuclear leukocytes (PMN). Neonatal TAs were rich in PMN containing BPI and expressed mRNAs encoding Toll-like receptor (TLR) 4, CD14, and myeloid differentiation protein 2 (MD-2). Extracellular BPI was consistently detectable and correlated with TA PMN and GA. Both extracellular- and cellular-BPI increased during the first postnatal week. TA extracellular BPI, LBP, and SCD14 were positively correlated. TAs from intubated neonates demonstrate endotoxin accumulation and mobilization of endotoxin-directed innate immunity, potentially contributing to pulmonary inflammation. (Pediatr Res 66: 191-196, 2009)
\end{abstract}

$I^{n}$ nnate immunity of the newborn is functionally distinct from that of adults $(1,2)$ with respect to the expression of pattern recognition receptors, signaling adaptor proteins, and host defense effector molecules (3). Innate immunity of newborns to Gram-negative bacteria (GNB) and GNB-derived endotoxin or lipopolysaccharide (LPS) is of interest because 1) GNB are common intestinal commensal flora, 2) GNB are life-threatening neonatal pathogens (4), and 3) multiple diseases of prematurity

Received January 21, 2009; accepted March 25, 2009.

Correspondence: Ofer Levy, M.D., Ph.D., Division of Infectious Diseases, Department of Medicine, Children's Hospital Boston, 300 Longwood Avenue, Enders 854, Boston, MA 02115; e-mail: ofer.levy@ childrens.harvard.edu

Supported by the National Institutes of Health Specialized Center of Research (SCOR) Grant (HL72931), National Institutes of Health National Center for Research Resources K30 Grant (RR022292-07), the Thrasher Research Fund, and an unrestricted grant from XOMA (U.S.) L.L.C. are associated with endotoxin including sepsis (5), bronchopulmonary dysplasia (6), necrotizing enterocolitis (7), and cerebral palsy due to intracranial white matter damage (8).

Humans are highly sensitive to very low concentrations (picograms $/ \mathrm{mL}$ ) of endotoxin. This reflects efficient and sequential humoral and cell-based protein-endotoxin and protein-protein interactions involving LPS-binding protein (LBP), membrane and soluble forms of CD14, myeloid differentiation protein 2 (MD-2), and toll-like receptor (TLR)-4 (9,10). Sensitivity to endotoxin can be dampened by changes in expression of these proteins (11) as competition with other LBPs precludes transfer of LPS to CD14 and to the MD-2/TLR4 receptor complex on monocytes (12). Endotoxin induces tracheobronchial epithelial cell production of antimicrobial peptides (13) and cytokines that recruit and activate polymorphonuclear leukocytes (PMN) (14).

PMN play key roles in innate immunity deploying both oxygen-dependent and independent means to dispose of pathogens and neutralize their toxins (15). Bactericidal/permeabilityincreasing protein (BPI) is a cationic, $55-\mathrm{kD}$ protein of PMN primary granules that possesses anti-infective activities against GNB: endotoxin neutralization based on high affinity $(\mathrm{nM})$ binding of BPI to the lipid A region of LPS, bactericidal activity via membrane permeabilization, and opsonic activity (16). Human newborn cord blood PMN are deficient in BPI: full-term neonatal cord blood PMN contain $\sim 25-33 \%$ of adult PMN BPI (17), and preterm human cord blood demonstrates impaired stimulusinduced release of extracellular BPI (18).

Endotoxin could contribute to airway inflammation in mechanically ventilated human newborns by inducing tracheobronchial epithelial cell NF- $\kappa$ B activation $(19,20)$ and consequent production of cytokines or chemokines that recruit or activate PMN $(14,19,21,22)$. Accordingly, endotoxin instillation in the lungs of mechanically ventilated preterm lambs impairs gas exchange and induces systemic inflammation, mimicking aspects of severe lung disease in preterm humans (23).

Abbreviations: BPI, bactericidal/permeability-increasing protein; GNB, Gram-negative bacteria; LBP, LPS-binding protein; LPS, lipopolysaccharide; MD-2, myeloid differentiation protein 2; PMN, polymorphonuclear leukocytes; qRT, quantitative real time; sCD14, soluble cell differentiation antigen 14; TA, tracheal aspirate; TLR, toll-like receptor; TP, total protein 
Endogenous protein mediators of innate immunity are expressed in a GA-dependent manner (3,24-26). Relative to adults, human newborns are deficient in BPI content of cord blood PMN $(17,18)$ and serum concentrations of the liverderived acute phase reactants LBP and soluble cell differentiation antigen 14 (sCD14; 3). However, neonatal expression of these LPS-modulating proteins at inflammatory sites, such as tracheal aspirates (TAs), has not been reported. We undertook an observational study to characterize the presence of endotoxin and mobilization of endotoxin-modulating proteins in TAs of critically ill human newborns. We demonstrate endotoxin and early mobilization of endotoxin-directed innate immunity in respiratory secretions of intubated newborns, suggesting a possible role for endotoxin in pulmonary inflammation.

\section{METHODS}

Using an institutional review board (IRB)-approved protocol (Partners Human Research Committee), TA samples were collected from mechanically ventilated newborns $(n=42)$ at the Brigham and Women's Hospital NICU. Informed consent was not required as TAs are discarded specimens. GA ranged from 23 to $40 \mathrm{wk}$ (mean 28), and $70 \%$ were male. Preterm neonates were intubated for respiratory failure (surfactant deficiency; $n=38$ ), whereas full-term neonates were intubated for surfactant deficiency $(n=2)$, pneumonia $(n=1)$, and persistent pulmonary hypertension $(n=1)$. TAs were collected after endotracheal instillation of $0.5 \mathrm{~mL} / \mathrm{kg}$ sterile, pyrogen-free saline using sterile suction catheters and placed on ice for processing within $4 \mathrm{~h}$. Because of TA volume constraints, subsets of samples were analyzed for different markers, with $n$ provided in each figure legend.

Collection of neonatal TAs. After centrifugation $\left(700 \mathrm{~g}, 7 \mathrm{~min}\right.$ at $\left.4^{\circ} \mathrm{C}\right)$ and collection of TA supernatants, TA pellets were subjected to hypotonic lysis (sterile, pyrogen-free water; Baxter, Deerfield, IL) to remove erythrocytes $\left(\sim 45 \mathrm{~s}\right.$ at $\left.4^{\circ} \mathrm{C}\right)$, and $5 \%$ saline was added [final $(\mathrm{NaCl})=0.14 \mathrm{M}$ ] before washing (Hanks' Balanced Salt Solution without divalent cations). TA PMN were enumerated by microscopy of Wright's stained aliquots (Shandon Cytospin 3; Thermo Fisher Scientific, Waltham, MA), typically demonstrating $\geq 70 \%$ PMN. Cell viability (trypan blue exclusion) was $\geq 80 \%$. TA pellets and supernatants were stored at $-80^{\circ} \mathrm{C}$ before batch analysis.

Measurement of endotoxin. Endotoxin was measured using the Limulus amoebocyte lysate (LAL) assay according to the manufacturer's instructions (Charles River, Boston, MA).

PMN isolation. PMN were isolated from adult whole blood by dextran sedimentation and Ficoll-hypaque gradient centrifugation, using pyrogen-free reagents, as previously described (17), and enumerated by automated cell count and differential ( $\geq 85 \%$ pure; ADVIA 2120 , Siemens Medical Solutions Diagnostics, Tarrytown, NY), before storage at $-80^{\circ} \mathrm{C}$.

Sulfuric acid extraction of PMN BPI. Cell extracts were prepared using sonication and sulfuric acid, as previously described (17).

Western blotting. PMN acid extracts $\left(5 \times 10^{5} \mathrm{PMN}\right.$ equivalents/well $)$ were fractionated by SDS-PAGE. Western blotting used anti-BPI goat serum and $\mathrm{I}^{125}$ protein $\mathrm{G}$ as previously described (17), providing BPI detection in the 10-200 ng range. rBPI-50, a kind gift from XOMA (US) LLC, was used as BPI standard.

Measurement of soluble BPI, LBP, and CD14. ELISAs for the measurement of BPI and LBP (Hycult Biotechnology, Holland) and sCD14 (R\&D Systems, MN) were used according to the manufacturer's instructions.

Total protein measurement. The Bradford protein assay (Bio-Rad Laboratories, Inc. Hercules, CA) was used with human serum albumin as standard.

Antibacterial activity. Activity of PMN acid extracts against the serumresistant BPI-sensitive bacteremic isolate Escherichia coli $\mathrm{K} 1 / \mathrm{r}$, a K1encapsulated rough LPS chemotype strain, was measured as previously described $(17,27)$ and expressed as \%viability (ratio to input inoculum).

Isolation of RNA. RNA in TA pellets $\left(3 \times 10^{5}-10^{6} \mathrm{TA}\right.$ cells) was purified according to the manufacturer's instructions (RNeasy Plus Mini Kit; Qiagen, Valencia, CA) either immediately or after storage $\left(-80^{\circ} \mathrm{C}\right)$ in RNA Cell Protect Reagent (Qiagen).

Quantitative real-time PCR. cDNA was prepared using the $\mathrm{RT}^{2}$ First Strand Kit and treated with DNase (Superarray, Frederick, MD) before measurement of relative mRNA abundance by quantitative real-time PCR (qRT-PCR; SuperArray), using an ABI Prism 7000 Sequence Detector (Applied Biosystems, Foster City, CA). RT ${ }^{2}$ SYBR Green/ROX qPCR Master Mix was added to cDNA according to the manufacturer's instructions (Su-
perArray). Expression levels were normalized to housekeeping genes using the $\Delta \mathrm{Ct}$ method.

Flow cytometry. Fc binding sites on TA cells were blocked using $10 \%$ normal human serum (60 min RT) to prevent nonspecific binding. To detect granulocytes, cells were surface stained (20 min RT) with FITC-conjugated anti-CD66b MAb (mouse IgM, clone G10F5) at $5 \mu \mathrm{L} / 5 \times 10^{5}$ cells or the corresponding FITC-conjugated isotype control (mouse IgM, clone G155228; BD Pharmingen, San Jose, CA). After washing (Stain Buffer; BD Pharmingen) and permeabilization $(1 \times$ fluorescence-activated cell sorter lysing solution with $1 \times$ permeabilization or wash buffer containing saponin; BD Pharmingen, 10 min RT), BPI was detected by staining (20 mins RT) with anti-BPI MAb (mouse IgG1( $\kappa$ ), clone HM2042; HyCult Biotechnology, Uden, Holland) or isotype control (mouse $\operatorname{IgG1}(\kappa)$, clone MOPC-21; BD Pharmingen), followed by incubation (20 min RT) with a secondary phycoerythrin-conjugated MAb (rat anti-mouse IgG1( $\kappa$ ), clone A85-I; BD Pharmingen) at $5 \mu \mathrm{L} / 5 \times 10^{5}$ cells. Cells were preserved overnight ( $1 \%$ formalin and stain buffer, $4^{\circ} \mathrm{C}$ ) before analysis by flow cytometry (Cytomation MoFlo flow cytometer) and analyzed with Summit Software (v. 4.3, Dako, CO).

Fluorescent and confocal microscopy. Formalin-fixed cell preparations were imaged on a Nikon TE-2000 inverted microscope fitted with a video-rate confocal system: spinning disk confocal head (Yokogawa, Newnan, GA), $\mathrm{Kr} / \mathrm{Ar}$ laser illumination source (Melles Griot, Carlsbad, CA), fluorescence filters, and an Orca ERG cooled CCD camera (Hamamatsu, Hamamatsu, Japan). Image capture and 3D rendering used Slidebook software (Intelligent Imaging Innovations, Inc., Denver, CO). Confocal images were collected either as single 2D planes [paired with a differential interference contrast (DIC) view] or as 3D stacks (focal step size $0.3 \mu \mathrm{m}$ ).

Statistics. Statistical analyses used Prism 4.0a for MacIntosh (Graphpad Software, Inc., San Diego, CA) and SAS 9.1 (SAS Institute, Inc., Cary, NC). Antibacterial activity of neonatal TA and adult peripheral blood PMN extracts was compared using the unpaired $t$ test. Correlations were drawn using the Pearson or the Spearman method based on normality of the data. The nonparametric Mann-Whitney $U$ test was used for unequal variances (28). The $p$ values $\leq 0.05$ were considered significant.

\section{RESULTS}

We initially assessed whether endotoxin was detectable in a subset of TA supernatants. Fifteen of 37 (38\%) TAs tested positive for endotoxin. Endotoxin concentrations ranged from undetectable $(<0.01)$ to 2542 endotoxin units per milliliter $(\mathrm{EU} / \mathrm{mL})$ and positively correlated with postnatal age (Fig. 1A). TA PMN also increased with postnatal age (Fig. $1 B$ ) and correlated with TA endotoxin concentration (Fig. 1C).

To determine whether genes encoding endotoxin-modulating proteins are activated in TAs, we measured expression of endotoxin receptor components by qRT-PCR (Fig. 2). mRNAs encoding TLR4, MD-2, and CD14 were consistently detected ( $n=$ 6/6 TAs). In contrast, BPI mRNA was inconsistently $(n=4 / 6)$ detected at low levels $(<10$-fold ratio to lower limit of detection; not shown), and mRNA encoding the liver-derived acute phase reactant LBP was not detected $(n=0 / 6)$.

We next assessed whether BPI protein was detectable in TA pellets (Fig. 3). Bands corresponding to native BPI in adult PMN extracts were noted in premature neonatal TAs (rightmost lanes in Fig. 3) indicating expression of BPI in these samples, albeit at relatively lower amounts. Measurement of TA cellular BPI by ELISA of acid extracts (Fig. 4A) demonstrated mean cellular BPI concentrations of neonatal TA PMN nearly 3-fold lower than those of adult peripheral blood PMN. Accordingly, neonatal TA acid extracts were $\sim 3$-fold less potent than adult extracts with respect to killing of the BPI-sensitive clinical isolate E. coli K1/r (Fig. 4B).

To verify the source of BPI, we stained TA cells for the PMN marker CD66b and for intracellular BPI (Fig. 5). $\mathrm{CD} 66 \mathrm{~b}+/ \mathrm{BPI}+$ cells were readily detected in TAs (Fig. 

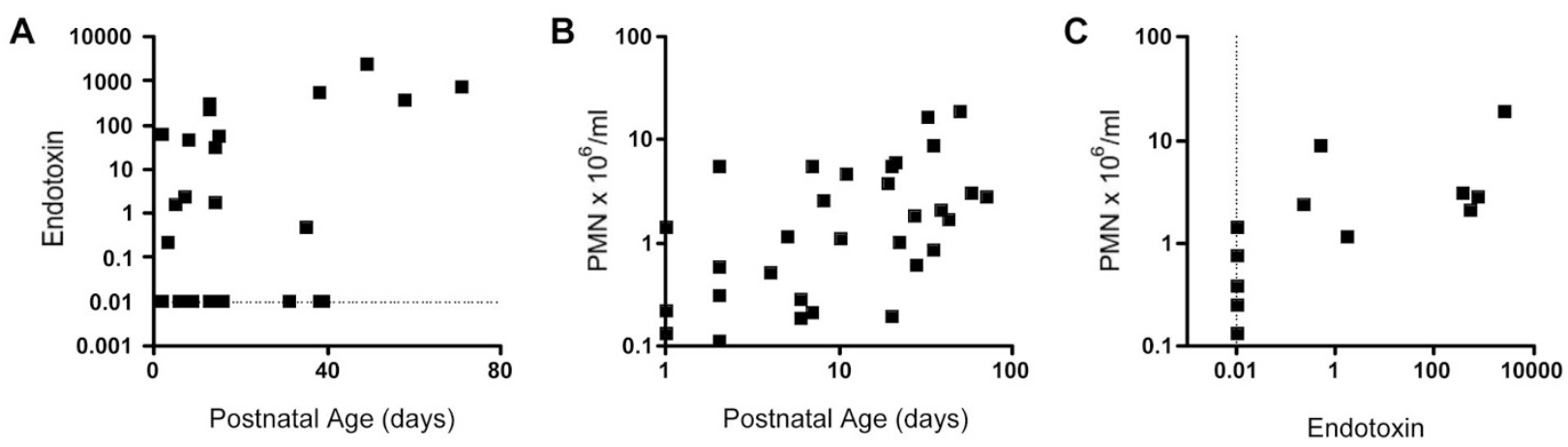

Figure 1. Endotoxin and PMN in neonatal TAs as a function of postnatal age. A, neonatal TA supernatants were assayed for endotoxin (endotoxin units/mL) using the LAL assay, and the data positively correlated with postnatal age both with respect to the total data set $(n=34$, Spearman $r=0.38, p<0.05)$ and in a subanalysis of endotoxin-positive samples $(n=15$, Spearman $r=0.59, p<0.05)$. B, TA PMN $\left(10^{6} / \mathrm{mL}\right)$ also increased with postnatal age $(n=35$, Spearman $r=0.46, p<0.01)$ and $C$, correlated with TA endotoxin concentration $(n=12$, Spearman $r=0.79, p<0.01)$. The dotted line represents samples negative for endotoxin.

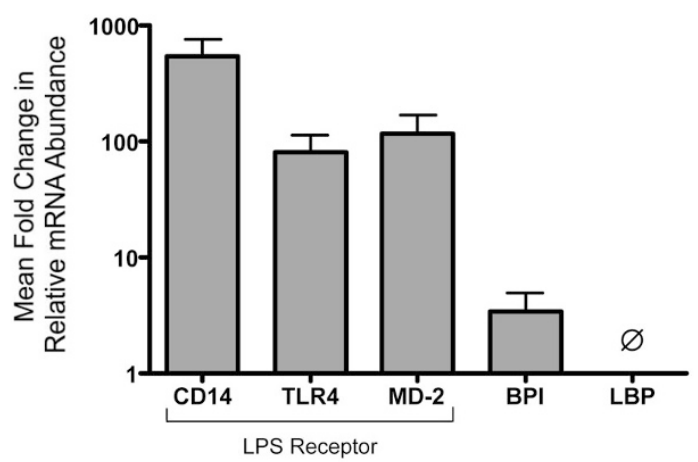

Figure 2. TA cells express endotoxin receptor components CD14, TLR4, MD-2, and BPI. TA pellet RNA was analyzed by qRT-PCR. mRNA levels are expressed as mean \pm SEM mRNA abundance relative to housekeeping controls as a ratio to the lower limit of detection. mRNA for proteins encoding LPS receptor components TLR4, CD14, and MD-2 were consistently detected $(n=6 / 6$ TAs tested; mean GA $=29$ wk $)$. BPI was detected in $4 / 6$ TAs. In contrast, LBP mRNA was not detected (0/6 TAs tested).

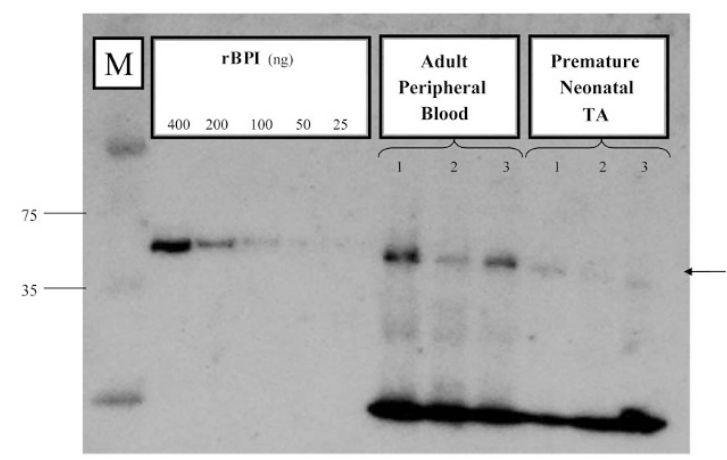

Figure 3. Neonatal TA PMN express cellular BPI. Cell pellets were solubilized and fractionated by SDS-PAGE $\left(5 \times 10^{5}\right.$ PMN equivalents per lane $)$ for Western blotting as described in the Methods section. In addition to molecular weight markers $(M$; sizes indicated in $\mathrm{kD})$, 2-fold dilutions of pure recombinant holo-BPI (rBPI) were included as standard. In this representative example, PMN samples from three adults (peripheral blood PMN) and three preterm newborns (TA cells) were analyzed. Premature neonatal TAs demonstrate relatively weak expression of the $\sim 55 \mathrm{kD}$ protein (arrow).

$5 B$ ), and most ( $>95 \%)$ BPI-positive cells were PMN. Confocal fluorescent and DIC imaging also demonstrated CD66b $+/$ BPI + cells (Fig. $5 G$ and $I$ ).
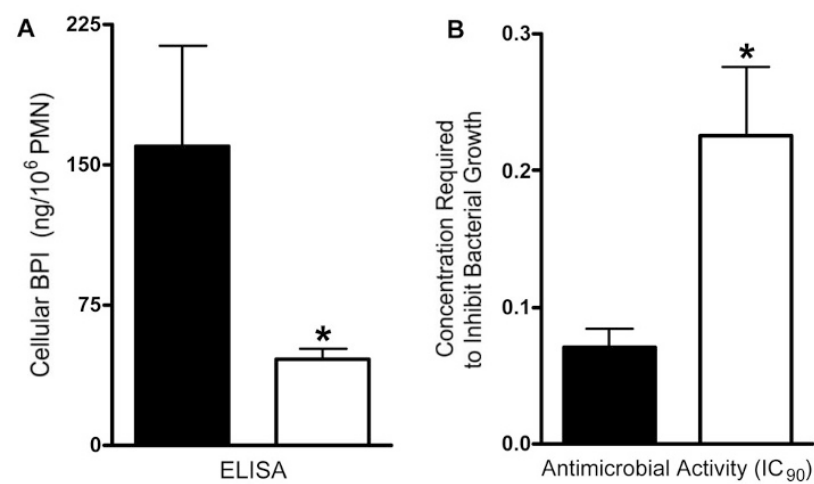

Figure 4. Neonatal TA PMN contain lesser amounts of cellular BPI than adult peripheral blood PMN. A, BPI content of acid extracts of neonatal TA PMN (mean \pm SEM of $46 \pm 6 \mathrm{ng} / 10^{6} \mathrm{PMN} ; n=8$ ) and adult peripheral blood PMN $\left(160 \pm 54 \mathrm{ng} / 10^{6} \mathrm{PMN} ; n=6\right)$ were determined by ELISA; ${ }^{*} p<$ 0.05 , unpaired $t$ test. $B$, BPI-mediated killing activity of PMN acid extracts as measured by the concentration of PMN required to inhibit $90 \%$ of bacterial growth $\left(\mathrm{IC}_{90}\right)$ was measured in vitro against the BPI-sensitive neonatal pathogen E. coli $\mathrm{K} 1 / \mathrm{r}$. Extracts of neonatal TA PMN had less antibacterial activity (mean $\pm \mathrm{SEM}, \mathrm{IC}_{90}=0.226 \pm 0.050 \%, n=8$ ) than extracts of adult PMN ( $\left.\mathrm{IC}_{90}=0.070 \pm 0.013 \%, n=6\right), * p<0.05$, unpaired $t$ test.

We next characterized extracellular BPI expression and its correlates. Extracellular BPI was detectable $(>0.1 \mathrm{ng} / \mathrm{mL})$ in $>98 \%$ of TAs (range $4-7920 \mathrm{ng}$ extracellular BPI/mL TA supernatant). Extracellular BPI positively correlated with TA PMN content (Fig. 6A) even after adjustment for total protein (TP; Fig. 6B). Extracellular BPI concentrations in TAs sampled during the first two postnatal days also correlated with GA (Fig. 6C) even when adjusted for TP (Fig. 6D). TA PMN count and GA did not correlate (not shown).

Under basal conditions, most PMN BPI are intracellular and degranulation of BPI can occur during inflammation (29). We assessed the relative expression of BPI in the cellular and extracellular fractions of neonatal TAs. Cellular BPI (TA pellet extracts) and extracellular BPI (TA supernatants) were measured by ELISA. Data were analyzed after adjusting for both TP content and PMN count. Representative data from a subset of subjects in Fig. 7 demonstrate that the majority (79-99\%) of neonatal TA BPI remained cell associated. 


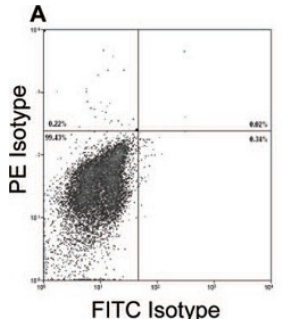

B

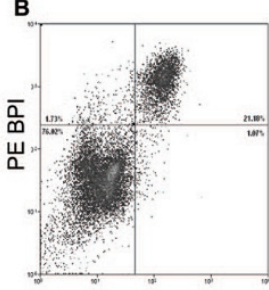

FITC CD66b

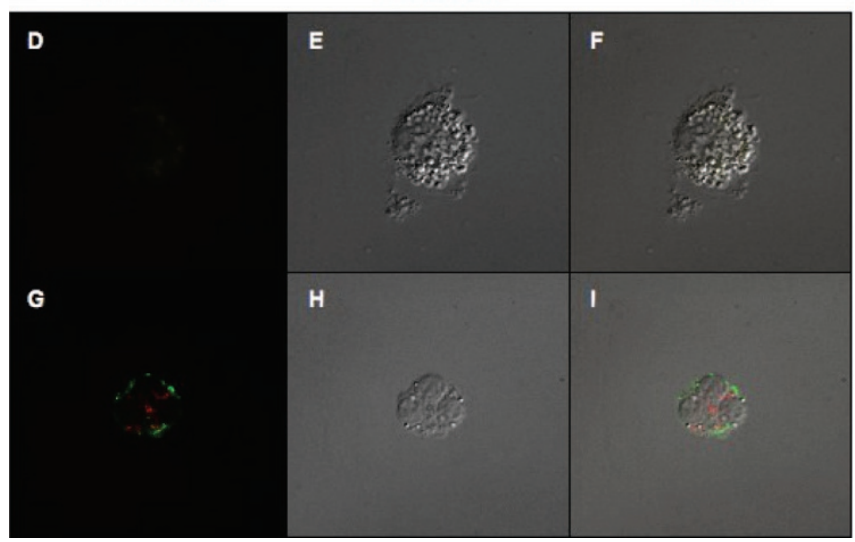

Figure 5. PMN are the primary source of BPI in neonatal TAs. Representative flow cytometry of neonatal TA cells ( $28 \mathrm{wk}$ GA male): A, stained with both FITC- and PE-labeled isotypes, with background staining set at 1\%. $B$, staining with FITC-labeled granulocyte cell surface antigen CD66b and intracellular phycoerythrin-labeled BPI. Most CD66b + cells were also BPI+. Percentages of the total amount of cells are given within the charts for each quadrant. $C$, This histogram depicts a shift in median fluorescence for BPI-positive cells (shaded) vs the isotype (dashed line). Confocal fluorescent images $(D$ and $G$ ), differential interference contrast (DIC) images ( $E$ and $H$ ), and DIC or confocal fluorescent image overlay $(F$ and $I)$ depict TA cells stained with FITC isotype $(D, E$, and $F$ ) or with extracellular FITC-labeled CD66b and intracellular PE-labeled BPI $(G, H$, and $I$ ). Double positive immunofluorescence is seen in $(G)$ and $(I)$.
A

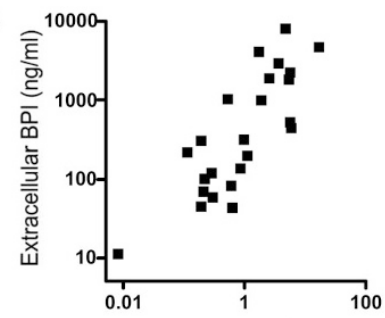

TA PMN $\times 10^{6} / \mathrm{ml}$

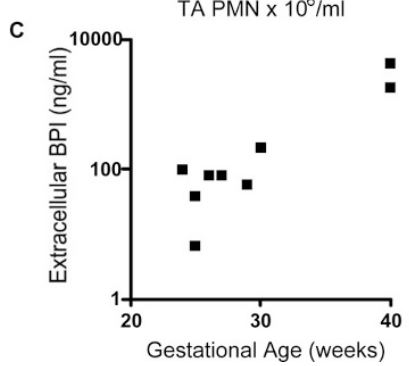

B

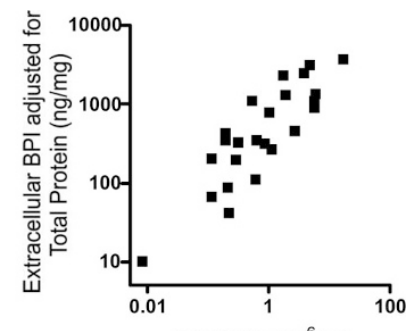

TA PMN $\times 10^{6} / \mathrm{ml}$

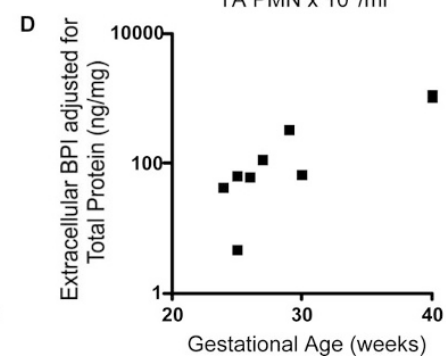

Figure 6. Extracellular BPI correlates with TA PMN content and gestational age. Extracellular BPI (ELISA of TA supernatants) correlated positively with TA PMN content ( $n=13$ subjects) both by unadjusted measures ( $A$; Spearman $r=0.73, p<0.0001)$ and when normalized for TP ( $B$; Spearman $r=0.79, p<0.0001)$. Extracellular BPI of TAs collected during the first postnatal week correlated positively with increasing GA both by unadjusted measures $(C ; n=9$, Spearman $r=0.69, p<0.05)$ and when normalized for TP $(D$; Spearman $r=0.89, p<0.005)$.

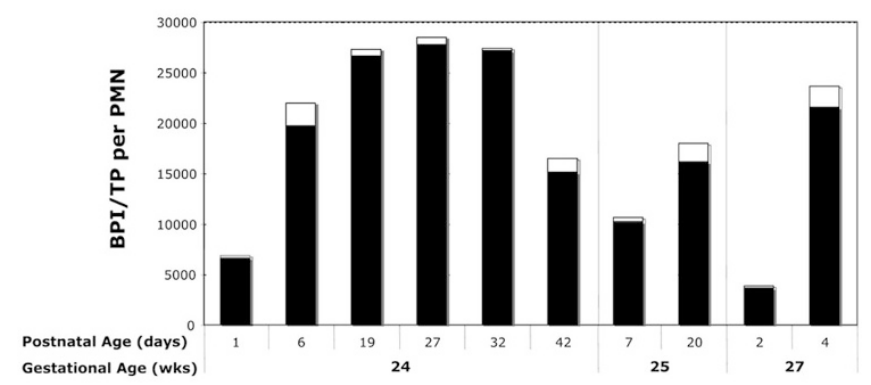

Figure 7. BPI in neonatal TAs is predominantly cell associated. Representative data ( $n=3$ subjects) sampled at 2-6 postnatal time points, as indicated. BPI in PMN acid extracts of TA pellets (cellular BPI) and TA supernatants (extracellular BPI) was measured by ELISA and adjusted for TP and PMN count. Most TA BPI is in the form of cellular BPI (filled black bars), with a lesser proportion of extracellular BPI (white extensions at top of bar graphs).

Extracellular BPI normalized for TP also increased with postnatal age, independently of GA (Fig. 8A). When the analysis was dichotomized by postnatal age, extracellular BPI adjusted for TP increased significantly over the first postnatal week (Fig. 8B). Indeed, cellular BPI adjusted for TP and PMN count increased significantly in the first postnatal week (Fig. $8 C$ ). Cellular and extracellular BPI did not correlate (not shown) suggesting that increased cellular BPI content of TA PMN during the first week of life was not secondary to reduced release of extracellular BPI.

LBP and SCD14 were readily detected in neonatal TA supernatants (mean \pm SEM: LBP $106 \pm 25 \mathrm{ng} / \mathrm{mL}$; sCD14 $68 \pm 13 \mathrm{ng} / \mathrm{mL}$ ) and correlated with extracellular BPI. Extracellular BPI positively correlated with LBP (Fig. 9A) and sCD14 (Fig. 9B). LBP also positively correlated with sCD14 (Fig. 9C).

\section{DISCUSSION}

We have characterized for the first time the presence of endotoxin and the expression of key endotoxin-modulating proteins in TAs of an observational cohort of mechanically ventilated human infants. We show that endotoxin is present in tracheal secretions, especially after prolonged intubation corresponding to early mobilization of endotoxin-directed innate immunity.

BPI is a key PMN-derived protein mobilized to tracheal secretions. Neonatal TA PMN express BPI antigen of identical molecular weight to that of adults, albeit at lower levels than adult peripheral blood PMN (Figs. 3 and 4). TA BPI is predominately cell associated (Fig. 7), consistent with the subcellular localization of BPI to PMN primary granules, which are less prone to extracellular degranulation (30). However, neonatal TA extracellular BPI was consistently detectable and correlated with TA PMN content (Fig. 6A and $B$ ), suggesting that PMN are the predominant source of BPI in these upper respiratory secretions.

TA BPI expression was both GA and postnatal age dependent: a) extracellular BPI concentrations during the first two postnatal days correlated with GA (Fig. $6 C$ and $D$ ), b) extracellular BPI adjusted for TP increased with postnatal age (Fig. $8 A$ and $B$ ), and c) cellular BPI adjusted for TP and PMN count 

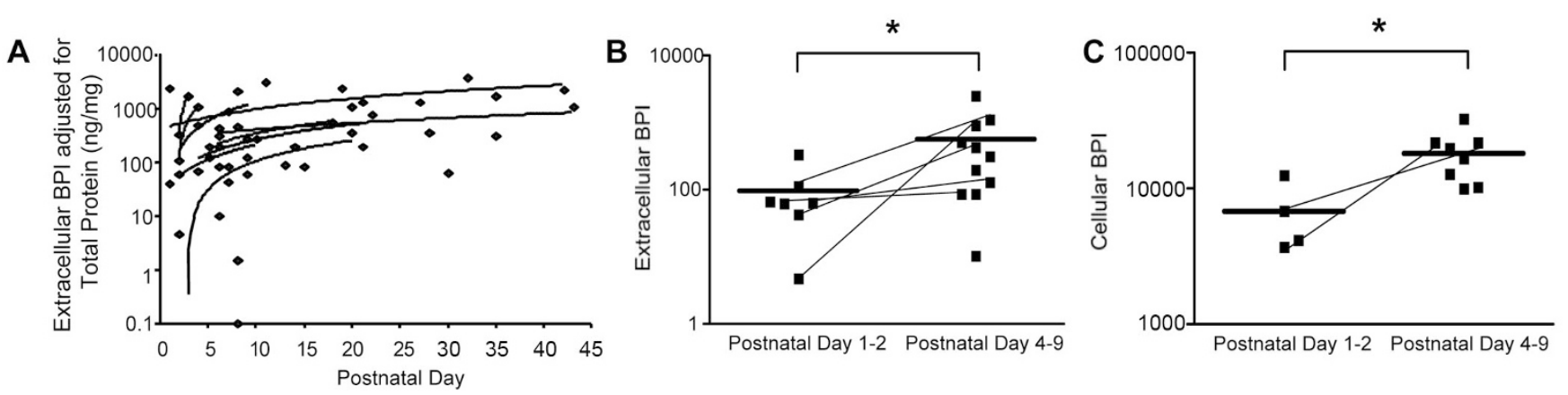

Figure 8. BPI increases with postnatal age. A, Extracellular BPI adjusted for TP is plotted as a function of postnatal age (d). Trend lines were fit to subjects for whom two or more samples were obtained. $B$, Extracellular BPI adjusted for TP rises significantly over the first postnatal week, from mean \pm SEM of $97 \pm$ 41 (postnatal d $1-2 ; n=7$ ) to $566 \pm 218 \mathrm{ng} \mathrm{BPI/mg} \mathrm{TP} \mathrm{(postnatal} \mathrm{d} 4-9 ; n=11$ ); $p<0.05$, Mann-Whitney. $C$, Cellular BPI, measured by ELISA of TA pellet extracts, rises from, mean \pm SEM, $6794 \pm 2038$ (postnatal d 1-2; $n=4$ ) to $18073 \pm 2642 \mathrm{ng}$ cellular BPI/mg TP $/ 10^{6}$ PMN (postnatal days $4-9 ; n=8 ; p<$ 0.05, Mann-Whitney). Lines connect data points for subjects for whom there are data at both time ranges.
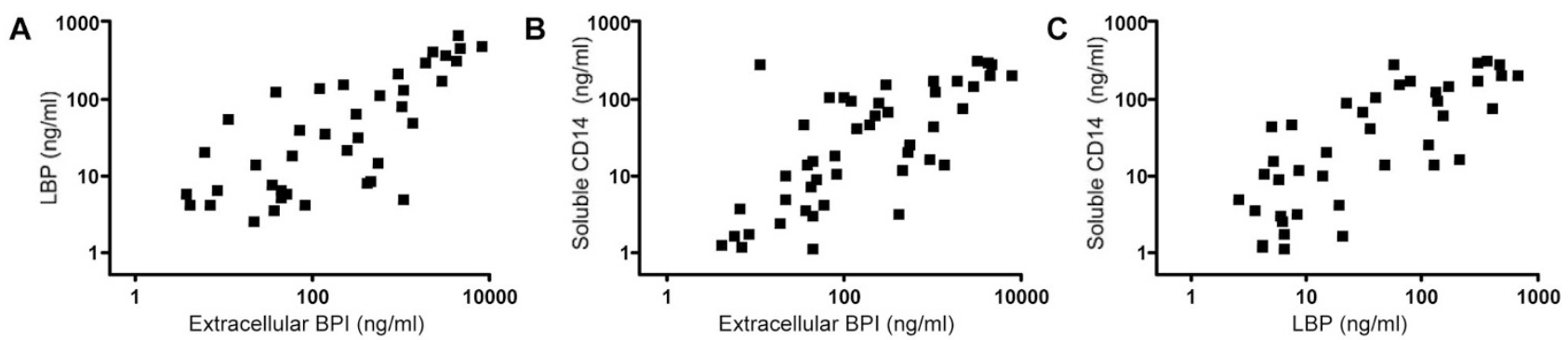

Figure 9. Positive correlation of extracellular BPI, LBP, and sCD14 in TA supernatants. ELISA measure of extracellular BPI, LBP, and sCD14 in TA supernatants reveals that extracellular BPI is positively correlated with $(A)$ LBP $(n=13$ subjects, Spearman $r=0.72, p<0.0001)$ and $(B)$ sCD14 $(n=15$ subjects, Spearman $r=0.73, p<0.0001)$, and also that $(C)$ LBP is positively correlated with sCD14 $(n=13$ patients, Spearman $r=0.75, p<0.0001)$.

specifically increased in the first postnatal week (Fig. 8C). Postnatal increases in cellular BPI might reflect developmental increases in availability or recruitment of more mature PMN and/or potential transcriptional activation of mature PMN (31) that can up-regulate gene expression (32).

In addition to substantial TA supernatant concentrations of extracellular BPI (mean $\sim 1 \mu \mathrm{g} / \mathrm{mL}$ ), we also detected substantial amounts of extracellular LBP $(0.3-680 \mathrm{ng} / \mathrm{mL})$ and sCD14 (0.5-315 ng/mL), concentrations in the bioactive range (11). Because TAs were obtained after endotracheal instillation of saline, they represent diluted samples, and true local airway fluid concentrations of these host defense proteins are likely even higher. Extracellular BPI was very likely derived from PMN based on correlation with PMN count (Fig. 6), flow cytometry, and confocal microscopy (Fig. 5). CD14 mRNA was abundant in TA pellets (Fig. 2), indicating possible local CD14 production, but we do not exclude contribution from a liver-derived acute phase response/plasma exudation $(11,33)$. LBP mRNA was not detected in TAs (Fig. 2), and its presence at the protein level may reflect respiratory epithelial cell production (34) and/or an acute phase response $(11,33)$. Positive correlations among extracellular BPI, LBP, and SCD14 in neonatal TA supernatants (Fig. 9) demonstrate coordinated mobilization of endotoxin-modulating proteins to the trachea of mechanically ventilated newborns.

Endotoxin (Fig. 1) introduced to the neonatal respiratory tract during peripartum infection and/or on endotracheal tube colonization could induce mobilization of endotoxin- modulating proteins to respiratory secretions. TLR-mediated activation of NF-kB and subsequent cytokine production may contribute to the mobilization of BPI, LBP, and SCD14 to the neonatal respiratory tract $(3,19)$. Maturation of pathways mediated by C/EBP epsilon, a transcription factor important for BPI expression (35), might underlie the postnatal increase in BPI expression. In mice, endotracheal LPS induces an IL-6mediated acute phase response, including LBP and sCD14 production (33). Moreover, during the first postnatal week, human newborns demonstrate increasing basal serum concentrations of IL-6 (36), a cytokine that is also detected in neonatal TAs (37). Consistent with such a mechanism of microbe-induced activation of innate immunity, our study documents that endotoxin is detected in TA supernatants, especially after prolonged intubation, and that multiple endotoxin-modulating proteins are up-regulated after intubation.

Our findings have potential clinical relevance. The magnitude and duration of exposure of the neonatal respiratory tract to endotoxin coupled with individual susceptibility to endotoxin-induced inflammation might contribute to susceptibility of newborns to a variety of endotoxin-associated conditions, as has been found in other settings (38-40). Indeed, the early presence of endotoxin likely contributes to recruitment of PMN to the trachea, which has been associated with subsequent chronic lung disease (41). Our characterization of endotoxin-directed innate immunity in this observational cohort sets the stage for testing such hypotheses in larger cohorts powered to correlate with clinical outcomes. To the extent that 
endotoxin plays a role in ventilator-associated lung inflammation and disease, potential prophylaxis and/or treatment might be forthcoming in the form of investigational endotoxin antagonists, including recombinant BPI congeners and lipid A antagonists (e.g. E5564), agents that safely reduce endotoxindriven inflammation in human studies in vivo (42-44).

Acknowledgments. We thank Drs. Michael Wessels, Richard Malley, and Tobias Strunk for their intellectual contributions, Kevin Chi for his assistance with PMN isolation, and Jessica Wagner of the Harvard Digestive Diseases Center Imaging Core for her assistance with confocal microscopy.

\section{REFERENCES}

1. Lewis DB, Wilson CB 2001 Developmental immunology and role of host defenses in fetal and neonatal susceptibility to infection. In: Remington J, Klein J (eds) Infectious Diseases of the Fetus and Newborn Infant. W.B. Saunders, Philadelphia, pp $25-138$

2. Adkins B, Leclerc C, Marshall-Clarke S 2004 Neonatal adaptive immunity comes of age. Nat Rev Immunol 4:553-564

3. Levy O 2007 Innate immunity of the newborn: basic mechanisms and clinical correlates. Nat Rev Immunol 7:379-390

4. Stoll BJ, Hansen N, Fanaroff AA, Wright LL, Carlo WA, Ehrenkranz RA, Lemons JA, Donovan EF, Stark AR, Tyson JE, Oh W, Bauer CR, Korones SB, Shankaran S, Laptook AR, Stevenson DK, Papile LA, Poole WK 2002 Changes in pathogens causing early-onset sepsis in very-low-birth-weight infants. [see comment]. N Engl J Med 347:240-247

5. Opal SM 2007 The host response to endotoxin, antilipopolysaccharide strategies, and the management of severe sepsis. Int J Med Microbiol 297:365-377

6. Jobe AH 2005 Antenatal associations with lung maturation and infection. J Perinatol 25:S31-S35

7. Caplan MS, Simon D, Jilling T 2005 The role of PAF, TLR, and the inflammatory response in neonatal necrotizing enterocolitis. Semin Pediatr Surg 14:145-151

8. Sherwin C, Fern R 2005 Acute lipopolysaccharide-mediated injury in neonatal white matter glia: role of TNF-alpha, IL-1beta, and calcium. J Immunol 175:155-161

9. Gioannini TL, Teghanemt A, Zhang D, Levis EN, Weiss JP 2005 Monomeric endotoxin:protein complexes are essential for TLR4-dependent cell activation. J Endotoxin Res 11:117-123

10. Prohinar P, Re F, Widstrom R, Zhang D, Teghanemt A, Weiss JP, Gioannini TL 2007 Specific high affinity interactions of monomeric endotoxin.protein complexes with Toll-like receptor 4 ectodomain. J Biol Chem 282:1010-1017

11. Kitchens RL, Thompson PA 2005 Modulatory effects of sCD14 and LBP on LPS-host cell interactions. J Endotoxin Res 11:225-229

12. Levy O 2000 A neutrophil-derived anti-infective molecule: bactericidal/ permeability-increasing protein. Antimicrob Agents Chemother 44:2925-2931

13. Ganz T 2002 Antimicrobial polypeptides in host defense of the respiratory tract. J Clin Invest 109:693-697

14. Neff SB, Z'Graggen BR, Neff TA, Jamnicki-Abegg M, Suter D, Schimmer RC, Booy C, Joch H, Pasch T, Ward PA, Beck-Schimmer B 2006 Inflammatory response of tracheobronchial epithelial cells to endotoxin. Am J Physiol Lung Cell Mol Physiol 290:L86-L96

15. Levy O 2004 Antimicrobial proteins and peptides: anti-infective molecules of mammalian leukocytes. J Leukoc Biol 76:909-925

16. Schultz H, Weiss JP 2007 The bactericidal/permeability-increasing protein (BPI) in infection and inflammatory disease. Clin Chim Acta 384:12-23

17. Levy O, Martin S, Eichenwald E, Ganz T, Valore E, Carroll S, Lee K, Goldmann D, Thorne G 1999 Impaired innate immunity in the newborn: newborn neutrophils are deficient in bactericidal/permeability-increasing protein (BPI). Pediatrics 104:13271333

18. Nupponen I, Turunen R, Nevalainen T, Peuravuori H, Pohjavuori M, Repo H, Andersson S 2002 Extracellular release of bactericidal/permeability-increasing protein in newborn infants. Pediatr Res 51:670-674

19. Shimotake TK, Izhar FM, Rumilla K, Li J, Tan A, Page K, Brasier AR, Schreiber MD, Hershenson MB 2004 Interleukin (IL)-1 beta in tracheal aspirates from premature infants induces airway epithelial cell IL-8 expression via an NF-kappa B dependent pathway. Pediatr Res 56:907-913

20. Cheng DS, Han W, Chen SM, Sherrill TP, Chont M, Park GY, Sheller JR, Polosukhin VV, Christman JW, Yull FE, Blackwell TS 2007 Airway epithelium controls lung inflammation and injury through the NF-kappa B pathway. J Immunol 178:6504-6513

21. Harris MC, D'Angio CT, Gallagher PR, Kaufman D, Evans J, Kilpatrick L 2005 Cytokine elaboration in critically ill infants with bacterial sepsis, necrotizing enter- colitis, or sepsis syndrome: correlation with clinical parameters of inflammation and mortality. J Pediatr 147:462-468

22. De Dooy J, Colpaert C, Schuerwegh A, Bridts C, Van Der Planken M, Ieven M, De Clerck L, Stevens W, Mahieu L 2003 Relationship between histologic chorioamnionitis and early inflammatory variables in blood, tracheal aspirates, and endotracheal colonization in preterm infants. Pediatr Res 54:113-119

23. Kramer BW, Ikegami M, Jobe AH 2002 Intratracheal endotoxin causes systemic inflammation in ventilated preterm lambs. Am J Respir Crit Care Med 165:463-469

24. Dorschner RA, Lin KH, Murakami M, Gallo RL 2003 Neonatal skin in mice and humans expresses increased levels of antimicrobial peptides: innate immunity during development of the adaptive response. Pediatr Res 53:566-572

25. Kai-Larsen Y, Bergsson G, Gudmundsson GH, Printz G, Jornvall H, Marchini G, Agerberth B 2007 Antimicrobial components of the neonatal gut affected upon colonization. Pediatr Res 61:530-536

26. Starner TD, Agerberth B, Gudmundsson GH, McCray PB Jr 2005 Expression and activity of beta-defensins and LL-37 in the developing human lung. J Immunol 174:1608-1615

27. Levy O, Sisson R, Kenyon J, Eichenwald E, Macone A, Goldmann D 2000 Enhancement of neonatal innate defense: effects of adding an N-terminal recombinant fragment of bactericidal/permeability-increasing protein (rBPI21) on growth and TNF-inducing activity of Gram-negative bacteria tested in neonatal cord blood ex vivo. Infect Immun 68:5120-5125

28. Pagano M, Gauvreau K 1993 Principles of Biostatistics. Duxbury Press, Belmont, CA

29. Opal SM, Palardy JE, Marra MN, Fisher CJ Jr, McKelligon BM, Scott RW 1994 Relative concentrations of endotoxin-binding proteins in body fluids during infection. Lancet 344:429-431

30. Borregaard N, Cowland JB 1997 Granules of the human neutrophilic polymorphonuclear leukocyte. Blood 89:3503-3521

31. Lennartsson A, Vidovic K, Pass MB, Cowland JB, Gullberg U 2006 All-trans retinoic acid-induced expression of bactericidal/permeability-increasing protein (BPI) in human myeloid cells correlates to binding of C/EBPbeta and C/EBPepsilon to the BPI promoter. J Leukoc Biol 80:196-203

32. Borregaard N, Sorensen OE, Theilgaard-Monch K 2007 Neutrophil granules: a library of innate immunity proteins. Trends Immunol 28:340-345

33. Vernooy JH, Reynaert N, Wolfs TG, Cloots RH, Haegens A, de Vries B, Dentener MA, Buurman WA, Wouters EM 2005 Rapid pulmonary expression of acute-phase reactants after local lipopolysaccharide exposure in mice is followed by an interleukin-6 mediated systemic acute-phase response. Exp Lung Res 31:855-871

34. Dentener MA, Vreugdenhil AC, Hoet PH, Vernooy JH, Nieman FH, Heumann D, Janssen YM, Buurman WA, Wouters EF 2000 Production of the acute-phase protein lipopolysaccharide-binding protein by respiratory type II epithelial cells: implications for local defense to bacterial endotoxins. Am J Respir Cell Mol Biol 23:146153

35. Tanaka M, Gombart AF, Koeffler HP, Shiohara M 2007 Expression of bactericidal/ permeability-increasing protein requires C/EBP epsilon. Int J Hematol 85:304-311

36. Angelone DF, Wessels MR, Coughlin M, Suter EE, Valentini P, Kalish LA, Levy O 2006 Innate immunity of the human newborn is polarized toward a high ratio of IL-6/TNF-alpha production in vitro and in vivo. Pediatr Res 60:205-209

37. Choi CW, Kim BI, Kim HS, Park JD, Choi JH, Son DW 2006 Increase of interleukin-6 in tracheal aspirate at birth: a predictor of subsequent bronchopulmonary dysplasia in preterm infants. Acta Paediatr 95:38-43

38. Jones CA, Holloway JA, Popplewell EJ, Diaper ND, Holloway JW, Vance GH, Warner JA, Warner JO 2002 Reduced soluble CD14 levels in amniotic fluid and breast milk are associated with the subsequent development of atopy, eczema, or both. J Allergy Clin Immunol 109:858-866

39. Gubern C, Lopez-Bermejo A, Biarnes J, Vendrell J, Ricart W, Fernandez-Real JM 2006 Natural antibiotics and insulin sensitivity: the role of bactericidal/permeabilityincreasing protein. Diabetes 55:216-224

40. Chien JW, Zhao LP, Hansen JA, Fan WH, Parimon T, Clark JG 2006 Genetic variation in bactericidal/permeability-increasing protein influences the risk of developing rapid airflow decline after hematopoietic cell transplantation. Blood 107:2200-2207

41. Huang HC, Tai FY, Wang FS, Liu CA, Hsu TY, Ou CY, Yang KD 2005 Correlation of augmented IL- 8 production to premature chronic lung disease: implication of posttranscriptional regulation. Pediatr Res 58:216-221

42. von der Mohlen MA, Kimmings AN, Wedel NI, Mevissen ML, Jansen J, Friedmann N, Lorenz TJ, Nelson BJ, White ML, Bauer R, Hack CE, Eerenberg AJ, van Deventer S 1995 Inhibition of endotoxin-induced cytokine release and neutrophil activation in humans by use of recombinant bactericidal/permeability-increasing protein. J Infect Dis 172:144-151

43. Lynen M, Rossignol DP, Wheeler JL, Kao RJ, Perdomo CA, Noveck R, Vargas R, D'Angelo T, Gotzkowsky S, McMahox FG 2003 Blocking of responses to endotoxin by E5564 in healthy volunteers with experimental endotoxemia. J Infect Dis 187:631-639

44. Levin M, Quint PA, Goldstein B, Barton P, Bradley JS, Shemie SD, Yeh T, Kim SS, Cafaro DP, Scannon PJ, Giroir BP 2000 Recombinant bactericidal or permeabilityincreasing protein (rBPI21) as adjunctive treatment for children with severe meningococcal sepsis: a randomised trial. Lancet 356:961-967 